\title{
Recent Results in Proton-Initiated and Non Proton-Initiated Cationic Polymerizations
}

\author{
Pierre SigWALT \\ Universite Pierre et Marie Curie, Laboratoire de Chimie Macromoléculaire \\ Tour 44-ler étage-4, Place Jussieu 75230 Paris Cédex 05, Frànce
}

(Received August 20, 1984)

\begin{abstract}
The mechanisms of initiation reactions of carbocationic polymerizations determine the nature of the counter-ions and then to a large extent the stability of the active centres and the importance of chain transfer. The fate of the initiator is examined in chemically initiated carbocationic polymerizations initiated with protonic acids and with Friedel Crafts catalysts. In this last case, the criteria proposed to distinguish between direct and cocatalysed initiation are discussed. This is related to the mechanisms of synthesis of block and graft copolymers and of polymers with well defined end groups. A discussion of the types of species active for polymer growth is then made. This is linked to the possible occurrence of pseudocationic polymerizations, to the existence of visible and invisible species and to the observations of polymodal molecular weight distributions. In the last part, the stability of the active centres is examined, and also the various assumptions made to explain the growth of molecular weight with conversion in several systems. The occurrence of living or "quasiliving" polymerizations and other possible explanations are discussed.
\end{abstract}

KEY WORDS Carbocationic Polymerizations / Initiation / Protonic Acids / Friedel Crafts Catalysts / Cocatalysis / Pseudocationic Polymerizations / Polymodal Distributions / Living Polymerizations / Quasi Living Polymerizations /

In a talk given in 1980 in Kyoto, at the International Symposium in Cationic Polymerization, I said that the central problem of cationic polymerization is that of the nature and concentration of the active species, and the situation is still the same even if some progress has been made. The interpretation of all the results obtained in the synthesis of new types of polymers or copolymers is dependent upon the mechanisms of initiation. They determine the nature and concentration of the "head groups" in at least some macromolecules, and also the nature and the reactivity of the active centres. Those will in turn determine the type of transfer and termination reactions that control molecular weights and the nature of the polymer end groups.

The most important unsolved problems are still persisting for carbocationic polymerizations of ethylenic monomers, since carbocations are extremely unstable, particularly near room tempera- ture. Quite understandably, the controversies are more frequent with these monomers, with sometimes quite opposite theories being offered. I shall not consider here ring-opening polymerizations in which active centres, being oniums ions, are much more stable and could be more easily identified. It is however obvious that the knoweldge in this field is more advanced and has influenced some interpretations of carbocationic polymerization.

During the last 5 years, many interesting informations have been published in the two related fields of reaction mechanisms and of synthesis of polymers with well defined end groups (and their copolymers). But only limited attempts have been made to put into perspective these various results and to distinguish between what is or is not well established for carbocationic polymerizations, about initiation, propagation and termination reactions for both proton-initiated and non proton 
initiated polymerizations. This attempt will be however restricted to initiation by Friedel Crafts catalysts and their adducts (with or without cocatalysis) and by strong protonic acids, and we shall not examine initiation by UV or ionizing radiations, or reactions supposedly occurring through electron transfer.

\section{THE INITIATION REACTION: FATE OF THE INITIATOR AND NATURE OF THE ACTIVE SPECIES}

One might have expected two completely different situations on one hand for strong protonic acids (such as perchloric or triflic) and on the other hand for Friedel Crafts catalysts, that have been both used in rather high concentrations $\left(10^{-4}\right.$ to $10^{-2} \mathrm{M}$ ). If cocatalysis is assumed in the second case, the maximum possible active center concentration should be much lower. But in fact, the active center concentrations are perhaps also much lower than the protonic acid concentration in the first case, and it has been assumed that most of the acid is either complexed with the monomer or gives an inactive ester. And on the other hand, when direct initiation involving only the monomer and the initiator occurs with Friedel Crafts catalyst, the active center concentration may be very high compared to those of the initiator.

Unfortunately, the distinction between cocatalyzed and direct initiation has generally been qualitative, with arguments being given for or against one or the other mechanism. But more recently, some quantitative data of the initiation yield into carbocations have been available, and some indirect data about the number of active centres could also be deduced from the total number of macromolecules, for reactions in which transfer was assumed to be absent. An interesting related problem is that of the synthesis of block or graft copolymers by cocatalyzed initiation.

\section{Initiation of Homopolymerizations by Friedel Crafts Catalysts or Their Complexes}

The first criteria for cocatalysis have been the "stopping experiments" such as those described by Evans and Plesch. ${ }^{1}$ More recently, another criterion has been suggested ${ }^{2}$ : the effect of hindered amines used as "proton traps."
Stopping Experiments. When a Friedel Crafts (F and C) catalyst does not initiate the polymerization of a monomer or if the reaction occurs only with limited conversion, and if it is started (again) by the addition of a substance, cocatalysis involving this substance is said to occur. This has been shown for several systems, the most studied being polymerization of isobutylene in $\mathrm{CH}_{2} \mathrm{Cl}_{2}$ by $\mathrm{TiCl}_{4}{ }^{1}$ or by $\mathrm{AlEt}_{2} \mathrm{Cl}$ with various cocatalysts $\left(\mathrm{HCl}^{3}{ }^{3} \mathrm{RCl},{ }^{4}\right.$ $\left.\mathrm{Cl}_{2} \cdots\right)$. Initiation has been generally assumed to occur by protonation involving a complex acid $\left(\mathrm{H}^{(+)} \mathrm{TiCl}_{4} \mathrm{OH}^{(-)}, \mathrm{H}^{(+)} \mathrm{AlEt}_{2} \mathrm{Cl}_{2}^{(-)}\right)$or addition of another cation $\left(\left(\mathrm{CH}_{3}\right)_{3} \mathrm{C}^{(+)} \mathrm{AlEt}_{2} \mathrm{Cl}_{2}{ }^{(-)},\left(\mathrm{Cl}^{(+)}\right) \cdots\right)$. However, the reaction of the cocatalyst with a complex of the monomer with the Lewis acid is sometimes more likely. But the nature of the counter ions in these reactions is in fact quite unknown, except perhaps for initiation by trityl salts, and one may also imagine other reactions, e.g.:

$$
\begin{aligned}
& \mathrm{TiCl}_{4}+\mathrm{H}_{2} \mathrm{O} \rightarrow \mathrm{TiCl}_{3} \mathrm{OH}+\mathrm{HCl} \text { (playing the part of } \\
& \text { a cocatalyst) } \\
& \rightarrow 1 / 2 \mathrm{Cl}_{3} \mathrm{TiOTiCl}_{3}+1 / 2 \mathrm{H}_{2} \mathrm{O} \text {, etc.. } \\
& \mathrm{AlEt}_{2} \mathrm{Cl}+\mathrm{HCl} \rightarrow \mathrm{AlEtCl}_{2}+\mathrm{EtH} \\
& \mathrm{AlEt}_{2} \mathrm{Cl}+\left(\mathrm{CH}_{3}\right)_{3} \mathrm{CCl} \rightarrow \mathrm{AlEtCl}_{2}+\left(\mathrm{CH}_{3}\right)_{3} \mathrm{CC}_{2} \mathrm{H}_{5}
\end{aligned}
$$

It has been suggested ${ }^{5}$ that $\mathrm{AlEtCl}_{2}$ formed in situ and in a nascent non associated form, might lead to a direct initiation.

Qualitative Arguments for Direct Initiation. Polymerizations by condensation from a vapor phase in high purity conditions showed that initiation of isobutylene by $\mathrm{TiCl}_{4}$ may occur in the gas phase but does not occur to a significant degree in the liquid phase. ${ }^{6}$ This was attributed to the direct interaction of monomer with catalyst, giving the active centres. Other arguments for direct initiation were the insensitivity to water concentration of the rates of $\alpha$-methylstyrene or indene polymerizations at low temperature.

These interpretations have been challenged on the ground that a minute quantity of cocatalyst might have been formed in a reproducible way. It was also suggested $^{7}$ that a photochemical initiation might have taken place, such as those observed by Marek et al. ${ }^{8}$ but this explanation is not satisfactory since results were the same when the experiments were carried out in darkness. ${ }^{6,9}$

Very recently evidence for a polymerization of 
isobutylene apparently not involving cocatalysis was given by Marek et al., who observed a fast "spontaneous" polymerization of quiescent mixtures of isobutylene with $\mathrm{TiCl}_{4}$ (in various solvents) when the temperature was lowered to the -110 $-140^{\circ} \mathrm{C}$ range. ${ }^{10}$

Good indirect arguments in favor of direct initiation have also been given by Plesch $e t$ al. for the polymerization of isobutylene in $\mathrm{CH}_{2} \mathrm{Cl}_{2}$ by $\mathrm{AlCl}_{3}$ and $\mathrm{AlBr}_{3} .{ }^{11}$

In non polar solvents, the strong enhancement of isobutylene polymerization when a mixture of $\mathrm{AlBr}_{3}$ and $\mathrm{TiCl}_{4}$ was used has been considered a strong indication that direct initiation could occur. ${ }^{12}$ However, a recent reexamination of these systems showed rates much lower than those previously found, ${ }^{13}$ even if the enhancement of the reaction rate compared to $\mathrm{AlBr}_{3}$ and $\mathrm{TiCl}_{4}$ used alone was confirmed. But since with 1,1-diphenylethylene (DPE) the carbocation yields were very low and not enhanced by the simultaneous presence of $\mathrm{AlBr}_{3}$ and $\mathrm{TiCl}_{4}$, the enhanced rate for isobutylene was attributed to the propagation reaction, and the occurrence of a cocatalyzed initiation could not be excluded. ${ }^{13}$

All these data show the difficulty of devising completely convincing experiments based on qualitative data and the superiority of arguments based on the quantitative determination of active center concentrations. It may naturally be argued that the behaviour of isobutylene is different from that of 1,1-DPE, but it was shown at least that direct initiation in a non polar solvent did not occur to a significant degree with this very reactive monomer (which is quite different from the situation in polar media, see below).

\section{Use of "Proton Traps" to Distinguish between Cocatalysed and Direct Initiation}

The addition to polymerizing systems of hindered bases such as 2,6-di-tert-butyl-4-methylpyridine (DBMP) to discriminate between direct initiation and proton donor cocatalyzed initiation has been suggested recently, ${ }^{2}$ and was based on the discriminating power of such a base that reacts easily with protons but apparently much less readily with other Lewis acids. It could be hoped that initiation involving proton donors would be completely inhibited while that occurring by direct initiation would not be, and various data seemed to support this hypothesis. For example, polymerization of isobutylene by $\mathrm{BF}_{3}-\mathrm{H}_{2} \mathrm{O}$ (in $\mathrm{C}_{2} \mathrm{H}_{5} \mathrm{Cl}$ ) was inhibited while that of $\alpha$-methylstyrene by $\mathrm{TiCl}_{4}-\mathrm{H}_{2} \mathrm{O}$ (in $\mathrm{CH}_{2} \mathrm{Cl}_{2}$ ) was not. ${ }^{2}$ This was taken as evidence of the absence of direct initiation in the first system (the cocatalysed one only being possible) and of the existence of direct initiation in the second one, occurring without interference of DBMP.

Some preliminary data with 1,1-diphenylethylene (DPE) initiated by $\mathrm{AlCl}_{3}$ in $\mathrm{CH}_{2} \mathrm{Cl}_{2}$ show that this reasoning is unwarranted - even if the conclusions might very well be true!- In this system, direct initiation occurs with a carbocation yield of $50 \%$ based on total $\mathrm{AlCl}_{3}$, and the carbocations formed at $-30^{\circ} \mathrm{C}$ or lower are quite stable, their concentration being easily measured by spectrophotometry. ${ }^{14}$ On the other hand, cocatalysed initiation by water is more rapid, with a yield of $133 \%$ per water molecule ${ }^{15}$ and may be easily distinguished from direct initiation. We found that no inhibition of cocatalysis by water was observed, the yield in carbocations during the first munutes of the reaction being very similar in the presence or absence of DBMP. ${ }^{16}$ This suggests that water cocatalysed initiation does not involve the formation of a free proton and occurs by a concerted mechanism. ${ }^{16} \mathrm{~A}$ similar conclusion was reached independently by Kennedy et al., ${ }^{17}$ for polymerizations of isobutylene, styrene and $\alpha$-methylstyrene that occurred in the presence of the proton trap 2,6-di-tert-butyl pyridine (DtBP), giving polymers with higher mol wt and narrower mol wt distributions that were attributed to scavenging of protons formed by spontaneous transfer reactions, propagation remaining unaffected. However, the initiations were supposed to occur exclusively by "water" cocatalysis, and the possibility of direct initiation or of cocatalysis involving $\mathrm{HCl}$ (both giving $\mathrm{M}_{t} \mathrm{X}_{n}{ }^{-}$ counter ions), was not considered.

Another tentative explanation of these last results might be that two mechanisms occur, giving different types of counterions, and that active centres formed by direct initiation or with $\mathrm{HCl}$ cocatalysis have counter ions (of the type $\mathrm{M}_{t} \mathrm{X}_{n}{ }^{-}$) less stable than those resulting from a water-cocatalysed initiation. The same interpretation might also be given for the suppression of the low mol wt tail in the presence of DBMP observed by Moulis et al. ${ }^{2}$ for the polymerization of $\alpha$-methylstyrene in $\mathrm{CH}_{2} \mathrm{Cl}_{2}$ by the system $\mathrm{TiCl}_{4}-\mathrm{H}_{2} \mathrm{O}$, but is opposite 
to that proposed by the authors.

This suggestion is supported by some of the results in the DPE- $\mathrm{AlCl}_{3}-\mathrm{H}_{2} \mathrm{O}$ system for which the destruction by DBMP of carbocations formed in part by direct initiation (counter-ion $\mathrm{AlCl}_{4}{ }^{-}$) was much more rapid than that of carbocations formed by water cocatalysis. ${ }^{16}$ One should recognize however that conclusions derived from the results for this initiator system are not necessarily valid for another one, and that similar studies are needed with other systems.

Moreover, the experiments with $\mathrm{AlCl}_{3}$ have shown that this catalyst interacts reversibly with DTBP $^{16}$ (equilibrium constant of about $10^{3}$ at $-30^{\circ} \mathrm{C}$ ) whereas $\mathrm{TiCl}_{4}$ does not, and this seems to lower strongly the reactivity with the active center of the amine complexed with $\mathrm{AlCl}_{3}$. It would be very interesting to investigate in conditions of high purity the possibility (or not) of direct initiation by $\mathrm{BCl}_{3}$, the role of $\mathrm{HCl}$ and $\mathrm{H}_{2} \mathrm{O}$ as potential cocatalysts, and the effect of hindred amines. This might help to explain interesting results obtained recently by Kennedy et al. For example, these authors observed that the polymerization of $\alpha$-methylstyrene in $\mathrm{CH}_{2} \mathrm{Cl}_{2}$ initiated by $\mathrm{BCl}_{3}$ at low temperatures leads to complete conversions in a few seconds, giving relatively low mol wt and polydisperse polymers (e.g., $M_{n}=20,000$ and $M_{w} / M_{n}=3.6$ at $-60^{\circ} \mathrm{C}$ ). With an excess of DTBP over $\mathrm{BCl}_{3}$, the yields were incomplete but the mol wt increased $\left(M_{n}=190,000\right.$ at $\left.-60^{\circ} \mathrm{C}\right)$ with narrowing of the distribution $\left(M_{w} / M_{n}=1.6\right)^{18}$. These results have been explained by the concept of terminative chain transfer, in which proton is formed first ("spontaneous" chain transfer) and is intercepted by DBP so that the kinetic chain is terminated, with no interference with the other events. This view was somewhat modified in a following paper, ${ }^{19}$ some limited transfer to monomer (by the standard bimolecular reaction) being acknowledged. It was also found that in the presence of DBP, the yields decreased (but the mol wt did not change) when the purification of the reagents increased, ${ }^{20}$ and this was attributed, I think logically, to polymerization initiated by water cocatalysis occurring by a concerted process not involving free protons.

In view of our results with 1,1-DPE and $\mathrm{AlCl}_{3}$ it may be suggested that in the absence of the amine, two types of initiation and propagation occur simultaneously, giving active centres with two different types of counter ions. One type could be $\mathrm{BCl}_{4}{ }^{-}$, formed either by the direct initiation reaction or by cocatalysis involving $\mathrm{HCl}$, and the corresponding active centre might be destroyed by the amine. The other type would involve an oxygen ligand $\left(\left(\mathrm{BCl}_{3} \mathrm{OH}\right)^{-}\right.$or $\left.\left(\mathrm{Cl}_{2} \mathrm{BOCCl}_{3}\right)^{-}\right)$, and would be much more stable, with no termination with the amine and little transfer until the completion of the reaction. The large increase of the mol wt however, seems to show that some other reactions may occur, that might be linked to the lowered rates (in presence of the amine) and to the longer reaction times (see Section III).

\section{Initiation Starting from a Preformed Polymer:} Synthesis of Block or Graft Copolymers

If reactive functional groups on a macromolecule are the starting point of the polymerization of another monomer, either block copolymers or graft copolymers may be obtained. If the number of blocks or grafts is equal to that of the reactive functional groups, this would be a strong evidence that blocking or grafting from (as defined by Kennedy ${ }^{21}$ ) occurred and an argument for the mechanism of initiation involving for example alkyl halides (as cocatalysts) or terminal reactive esters. However, this reasoning has been criticized by Gandini and Cheradame ${ }^{22}$ who pointed out that the blocking- or grafting-reactions might have occurred after the homopolymerization of the second monomer, through à polymer-polymer reaction.

The situation might be quite different according to the systems studied, and I think the three possibilities really exist: blocking or grafting from, grafting unto, or both together. We shall look at a few examples of block and graft copolymerizations.

\section{Block Copolymerizations.}

a. Styrene with Heterocycles. The first clearcut example is that of the block copolymerization of styrene with 1-tert-butylaziridine (AZ) given by Pepper, Goethals et al. ${ }^{23}$ Polymerization of styrene by $\mathrm{ClO}_{4} \mathrm{H}$ at $-78^{\circ} \mathrm{C}$ in $\mathrm{CH}_{2} \mathrm{Cl}_{2}$ and in the presence of $n$-butyl ammonium perchlorate $\left(n-\mathrm{Bu}_{4} \mathrm{NClO}_{4}\right)$ gave an incomplete conversion (30 to $50 \%$ ) of a low molecular weight polymer $\left(M_{n} \sim 1,500\right)$. The subsequent addition of $\mathrm{AZ}$ followed by a temperature rise to room temperature led to its polymerization, and the formation of block copolymers could be deduced from the GPC data on the final mixtures. 
This was interpreted as resulting from the presence in the polystyrene of perchloric ester end groups, inactive at low temperature but active with $\mathrm{AZ}$ at higher temperature. Since other types of reactions involving polystyrene and poly $\mathrm{AZ}$ are not easily imagined, this possibility seems quite likely.

b. Isobutylene and Vinylaromatics. The synthesis of polyisobutylenes terminated by tertiary chloride groups has been carried out with initiating systems based on $\mathrm{BCl}_{3}$ and cumylchloride (CC) or related multifunctional halides. With dicumyl chloride (DCC) linear polymers with two terminal $\mathrm{Cl}$ could be prepared, ${ }^{24,25}$ that were used for the initiation of styrene or $\alpha$-methylstyrene ${ }^{25}$ polymerization, $\mathrm{AlEt}_{2} \mathrm{Cl}$ being the catalyst. Rather low yields of isolated "triblocs" were obtained. ${ }^{25}$

When cumyl chloride was used however to prepare a monochloro polyisobutylene the results were much more complicated and difficult to explain, ${ }^{26}$ and with "tricumyl chloride" (TCC) the addition of an hindered amine (DtBP) was necessary in order to obtain a unimodal polyisobutylene. ${ }^{27}$ Moreover, in all cases, and according to mol wt, a variable proportion of terminal double bonds was formed, that decreased for higher mol wt polymers. ${ }^{27,28}$ This might mean that a slow addition chlorination reaction such as that observed by Plesch with aluminium chloride ${ }^{11}$ occurs with the terminal double bonds:

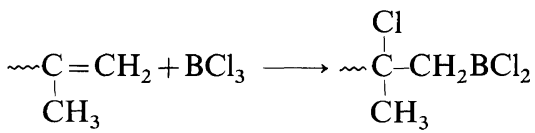

$$
\begin{aligned}
& \stackrel{\text { hydrolysis }}{\longrightarrow} \stackrel{\substack{\mathrm{Cl} \\
\mathrm{C}}}{\mathrm{C}}-\mathrm{CH}_{3}
\end{aligned}
$$

The copolymerization with another monomer might involve also the remaining terminal double bonds. If this was the case, the structure of the triblock and star copolymers would be more branched than expected.

The synthesis of block copolymers with vinyl ethers and $p$-methoxystyrene will be discussed in the last part of this paper.

Graft Copolymers. If a polymer bearing reactive chlorine atoms is reacted with a Friedel Crafts catalyst in the presence of a second monomer (B), grafting from carbocations formed on the backbone may occur. If this is the only type of initiation, one should obtain a graft copolymer, but also homopolymer of the second monomer if transfer also occurs. However, it was found when chlorobutyl rubber (CBR) was used as the backbone (with $\mathrm{AlEt}_{2} \mathrm{Cl}$ as catalyst) that the grafting efficiencies $\mathrm{GE}$ (i.e., grafted poly $\mathrm{B} /$ total poly $\mathrm{B}$ ) were much higher than expected for styrene ${ }^{29}$ and for indene. ${ }^{30}$ This was attributed by Kennedy et al. to the absence of transfer $^{29}$ and by ourselves to regrafting of the transferred chains on the CBR. ${ }^{30}$ We gave later two direct arguments in favor of grafting unto. First, when a polymer not containing double bonds, (a copolymer of isobutylene and $p$-chloromethylstyrene) was used as a backbone for the grafting of polyindene or polystyrene in identical conditions as above (e.g., at $-55^{\circ} \mathrm{C}$ in $\mathrm{CH}_{2} \mathrm{Cl}_{2}$ /methylcyclohexane), significant quantities of homopolyindene and homopolystyrene were formed, ${ }^{31}$ showing the occurrence of transfer. But with styrene there was also evidence of its partial regrafting on the polystyrene grafted branches (this does not occur significantly with polyindene). On the other hand, we showed that unsaturated rubber backbones (butyl rubber, EPDM) could also be grafted unto in the absence of halogen on the backbone, but with lower grafting efficiencies (GE).$^{30,32}$ The high GE for chlorobutyl rubber may be a consequence of the presence of very reactive $-\mathrm{CH}_{2}^{-}-$functions.

In order to explain the various results, another suggestion has been made by Gandini and Cheradame $^{22}$ : an exchange reaction might occur between $\mathrm{AlEt}_{2} \mathrm{Cl}$ (which does not give any direct initiation) and the macromolecular halide, giving birth to $\mathrm{AlEtCl}_{2}$ that may lead to a direct initiation. Grafting might then be in part or even mainly a grafting unto.

In order to prove that with the copolymer of $p$ chloromethylstyrene mentioned above, grafting occurred essentially by grafting from the chloromethyl groups (and that grafting unto was negligible in this case), we made recently some polymerizations of indene and styrene in the same conditions, but in the presence of a copolymer of isobutylene and styrene used as potential backbone. ${ }^{33}$ For polymerizations stopped exactly at $100 \%$ conversions, which was the case for all our experiments with the $p$ chloromethylstyrene copolymer, no graft copolymer was formed with indene, and a negligible proportion with styrene. This showed also the 
validity of this method of determination of transfer constants by the measurement of the grafting efficiency on the $p$-chlormethyl groups. ${ }^{31}$

Our conclusion is that both grafting from and grafting unto occur if the halogenated polymer backbone contains at the same time reactive halides and very reactive double bonds. However, if the double bonds are less reactive (such as in EPDM) large grafting efficiencies are observed only when temperatures are high enough. ${ }^{32}$

\section{MECHANISMS OF POLYMER GROWTH}

We have seen that in most carbocationic polymerizations, the concentration of the active species as well as their nature are not known. For polymerizations realized in polar solvents, they have generally been considered to be free ions and ion pairs, and this could be justified by the correlation sometimes observed between conductivity and polymerization rate. When Friedel Crafts catalysts are used, UV absorptions of carbocations unfortunately occur in the same wavelength range as those of the initiators and of their complexes with the monomer or the polymer, and data have been limited until now to 1,1-diphenylethylene ${ }^{15}$ (UV max $_{\text {max }}$ at and above $435 \mathrm{~nm}$ ) and 3-phenylindene. ${ }^{34}$

The advantage as initiators of strong protonic acids such as $\mathrm{ClO}_{4} \mathrm{H}$ or $\mathrm{CF}_{3} \mathrm{SO}_{3} \mathrm{H}$ is their transparency that permitted the observation around $350 \mathrm{~nm}$ of carbocations with a very limited lifetime ( 0.1 to a few seconds). But with both $\mathrm{ClO}_{4} \mathrm{H}^{35}$ and $\mathrm{CF}_{3} \mathrm{SO}_{3} \mathrm{H},{ }^{36,37}$ only a low yield of carbocations (1 to $5 \%$ of the acid) was observed with styrene, the fate of the remaining acid being unknown. Monomer was rapidly and completely consumed when monomer concentration was low, with relatively simple kinetics. But for higher monomer concentrations, the reaction was much slower and sometimes followed quite different kinetics. ${ }^{38}$ No free acid would be recovered by distillation in the case of perchloric acid, ${ }^{39}$ which seems to show it had been consumed completely by a reaction with the monomer.

The decrease of the polymerization rate when [M] grows could be explained satisfactorily by the variation of the dielectric constant $\varepsilon$ for a variation of [M] from 0.2 to $2 \mathrm{M}$ (in $\mathrm{CH}_{2} \mathrm{Cl}_{2}$ at $\left.0^{\circ} \mathrm{C}\right)^{40,41}$ but this does not explain the still largest increase in the rate when monomer concentration was down to about $0.01 . \cdot^{37,59}$

\section{Pseudocationic Polymerization}

This theory, that assumes that the active centres are perchloric acid esters, has been initially proposed by Plesch and Gandini ${ }^{42,43}$ to explain the absence of visible carbocations during the polymerization of styrene (at rather high concentrations) by this acid near room temperature. It was later shown that the only potential active site other than the ester should be the free carbocation $\left(\mathrm{P}^{+}\right),{ }^{44}$ since the lowest concentration of ionic species would be of the order of $10^{-6} \mathrm{M}$ and would be completely dissociated (at least, in solvents such as $\mathrm{CH}_{2} \mathrm{Cl}_{2}$ or $\mathrm{CH}_{2} \mathrm{ClCH}_{2} \mathrm{Cl}$ ).

However, it has already been said that the absence of UV absorption does not exclude the possibility of an ionic mechanism. ${ }^{39}$ For example, if $\left[\mathrm{ClO}_{4} \mathrm{H}\right]=10^{-3} \mathrm{M}$ and $\left[\mathrm{P}^{+}\right] \sim 10^{-6} \mathrm{M}$, the apparent rate constant $k_{\text {app }}\left(\sim 10\right.$ at $\left.20^{\circ} \mathrm{C}\right)$ is linked to $k_{\mathrm{p}}{ }^{+}$by the relationship

$$
\begin{aligned}
& k_{\mathrm{app}}\left[\mathrm{ClO}_{4} \mathrm{H}\right]_{0}=k_{\mathrm{p}}{ }^{+}\left[\mathrm{P}^{+}\right] \\
& 10 \times 10^{-3}=k_{\mathrm{p}}{ }^{+} \times 10^{-6} \\
& {k_{\mathrm{p}}}^{+}=10^{4}
\end{aligned}
$$

If $\left[\mathrm{P}^{+}\right] \sim 10^{-7}, k_{\mathrm{p}}^{+} \sim 10^{5}$ which is still a possibility in $\mathrm{CH}_{2} \mathrm{Cl}_{2} \cdot{ }^{36,37}$

The strongest argument ${ }^{43}$ against a propagation near room temperature involving free cations is the apparent absence of the effect of water (even in large excess over $\left.\mathrm{ClO}_{4} \mathrm{H}\right)$ on the reaction rate. ${ }^{40}$ However, it should be pointed out that in these experiments, the reagents were dried only over calcium hydride, and the residual water concentration may then be of the same order of magnitude as that of the acid $\left(3.5 \times 10^{-4} \mathrm{M}\right)$ so that the latter may be already hydrated before further water addition.

It has still to be understood why water would not inhibit completely any propagation involving free ions. In fact, the possibility of inhibition depends on the relative values of $k_{\mathrm{p}}{ }^{+}$and of the rate constant $k_{\mathrm{H}_{2} \mathrm{O}}$ of the reaction of $\mathrm{M}_{n}{ }^{+}$with water, together with monomer and water concentration. If both reactions are second order

$$
\frac{R_{\mathrm{p}}}{R_{\mathrm{t}_{\mathrm{H}, \mathrm{O}}}}=\frac{k_{\mathrm{p}}^{+}\left[\mathrm{M}_{n}^{+}\right][\mathrm{M}]}{k_{\mathrm{H}_{2} \mathrm{O}}\left[\mathrm{M}_{n}^{+}\right]\left[\mathrm{H}_{2} \mathrm{O}\right]}=\frac{k_{\mathrm{p}}^{+}}{k_{\mathrm{H}_{2} \mathrm{O}}} \frac{[\mathrm{M}]}{\left[\mathrm{H}_{2} \mathrm{O}\right]}
$$

Values of $k_{\mathrm{H}_{2} \mathrm{O}}$ are unfortunately not available, 
but the rate constant of the reaction of the benzyl cation with ethers and alcohols is of the order of $10^{7}$ to $10^{8} .^{45}$ If $k_{\mathrm{p}}{ }^{+}=2 \times 10^{53}$ and $k_{\mathrm{H}_{2} \mathrm{O}}=10^{7}$, the kinetic chain length $\lambda=R_{\mathrm{p}} / R_{\mathrm{t}_{\mathrm{H}} \mathrm{O}}=2.10^{-2}[\mathrm{M}] /\left[\mathrm{H}_{2} \mathrm{O}\right]$. For $[\mathrm{M}]=0.3 \mathrm{M}$ and $\left[\mathrm{H}_{2} \mathrm{O}\right]=3 \times 10^{-4} \mathrm{M}$, this leads to $\lambda=20$. This is compatible with the $\overline{\mathrm{DP}}_{n}$ observed for the low mol wt population but not with that of the high mol wt one. ${ }^{46,47}$ Since water does not seem to be consumed, its reaction with $\mathrm{M}_{n}{ }^{+}$would not be a termination but more probably a delayed transfer to monomer.

Polymerization of Styrene by Triflic Acid: Influence of Concentrations on the Kinetics. For relatively high $[\mathrm{M}]_{0} /[\mathrm{XH}]_{0}$ ratios $\left(\right.$ e.g., $\left.\sim 10^{3}{ }^{41}\right)$, a relatively slow reaction occurs (similarly to perchloric acid initiation) that is first order in monomer. This should be the consequence of either a quasi-stationary state or of the existence of stable active centres. For lower $[\mathrm{M}]_{0} /[\mathrm{XH}]_{0}$ ratios (e.g., 50 to $10^{2}$ ) a much more rapid non-stationary stage has been observed ${ }^{37}$ and a spectrophotometric stopped-flow method showed the simultaneous presence of carbocations, the concentration of which increased and then decreased very rapidly (in a fraction of a second at $0^{\circ} \mathrm{C}$ ) ${ }^{36,37}$ The yield in carbocations related to acid concentration was relatively low ( 1 to $5 \%$ ). The rapid stage has also been observed kinetically in some experiments made at $-15^{\circ} \mathrm{C}$ and was followed by the slow stage for some experiments made at low $\mathrm{M}$ and $\mathrm{XH}$ concentrations. ${ }^{49}$ This is similar to what was observed by Pepper with perchloric acid at $-60^{\circ} \mathrm{C} .^{46}$ If termination of the first stage gives the ester, the slow stage that follows may either involve directly the ester, or its activated form (by spontaneous ionization or ionization involving some free acid). The lowering of the rates of the slow stage with increasing monomer concentrations has been explained by the inhibiting effect of the formation of an acid-monomer complex, ${ }^{38,49}$ but the formation of an inactive ester seems more likely. Higher monomer concentrations might lower the free acid concentration.

The initial apparent rate constants $k_{\mathrm{app}}=R_{0} /$ $[\mathrm{M}]_{0}[\mathrm{HA}]_{0}$ observed by Kunitake et al. ${ }^{36,37}$ for the first stage reactions are much larger (by a factor of 50 to 100) than those of second stage reactions measured by Chmelir et al..$^{38}$ or Higashimura et $a l^{48}$ The very rapid formation of carbocations in the first non stationary stage is followed by their rapid disparition, giving probably the ester. The original kinetic treatment of Kunitake for initial rates $^{37}$ did not take into account the acid consumption and a possible reinitiation (necessary to explain the slow stationary stage). Assuming the following simple scheme:

$$
\begin{aligned}
& \mathrm{HA}+\mathrm{M} \stackrel{k_{\mathrm{i}}}{\longrightarrow} \mathrm{P}^{+} \\
& \mathrm{P}^{+} \underset{k_{\mathrm{ri}}}{\stackrel{k_{\mathrm{t}}}{\longrightarrow}} \mathrm{E} \\
& \mathrm{P}^{+}+\mathrm{M} \stackrel{k_{\mathrm{p}}}{\longrightarrow} \mathrm{P}^{+}
\end{aligned}
$$

the various rate constants have been estimated ${ }^{50}$ using the computer simulations of the kinetics based on the original data ${ }^{37}\left(\right.$ with $[\mathrm{M}]_{0} \simeq 0.3 \mathrm{M}$ and $[\mathrm{HA}]_{0} \simeq$ $\left.3 \times 10^{-3} \mathrm{M}\right)$. These simulations show that for $90 \%$ monomer conversion, more than $70 \%$ of the acid has been converted to the ester, and that for $97 \%$ monomer conversion, more than $95 \%$ of the acid has been converted. This may explain the very short lifetimes of carbocationic species and their low concentrations.

On the other hand, for a low acid concentration $\left(\sim 10^{-4} \mathrm{M}\right)$ the first stage is finished before $10 \%$ of the monomer is converted (see for example ref 49 ) and the second stage occurs with an equilibrium concentration of active species $\left[\mathrm{P}^{+}\right]_{\mathrm{e}} \simeq\left(k_{\mathrm{ri}} / k_{\mathrm{t}}\right)$ $\times[\mathrm{HA}]_{0} \simeq 0.01 \%$ of the acid used. It then seems that a variation in acid concentration might explain the predominance of either the first or the second stage.

However, another factor might also be involved, since for experiments made at high acid concentrations $\left(2.4\right.$ to $\left.9.8 \times 10^{-3} \mathrm{M}\right),{ }^{37}$ those were higher than the assumed water concentration in the system $\left(\leqslant 10^{-3} \mathrm{M}\right)$, whereas in other conditions, ${ }^{48}$ water concentration was considered higher than that of the acid $\left(3 \times 10^{-4}\right.$ versus $\left.2 \times 10^{-4} \mathrm{M}\right)$. An effect of water would be to give hydronium ions which have been shown to be much less reactive with the monomer than the non hydrated acid in experiments with 1,1-diphenylethylene. ${ }^{51}$ Water would lead to a lowering of the initiation rate and this might be enough to establish quasi-stationary conditions, not observed when "free" acid is involved.

Polymerization of Substituted Styrenes. With $p$ methoxystyrene at $30^{\circ} \mathrm{C}$ in similar conditions, the use of a stopped-flow apparatus permitted the observation of cationic species at $380 \mathrm{~nm}$ with a good correlation between the intensity of the maximum 
and the rate. ${ }^{52}$ Even if the evaluated carbocation concentration is quite approximative ${ }^{53}$ it is certainly much higher than for styrene. The attribution of the maxima to $p$-methoxystyryl cations has been already discussed ${ }^{53}$ and shall not be examined here. It has been shown later that these species are completely stable for a long time at $+10^{\circ} \mathrm{C}^{54}$

Very recently, experiments have been made with $\alpha$-methyl-p-isopropylstyrene at low temperature. ${ }^{55}$ There was at $-20^{\circ}$ a transient apparition at $362 \mathrm{~nm}$ of a carbocation, that was stable at $-40^{\circ} \mathrm{C}$ and below. Here again, the carbocation yields (even if they are uncertain by a factor of two) are very high (50 to $100 \%$ ).

A good correlation was found between the rate and the intensity of the UV maximum of the cations, that reached a constant concentration before a significant propagation takes place. This does not prove them to be the expected carbocations, and they might eventually be a more stable species with a longer lifetime, as is probably the case for $p$ methoxystyrene. But this shows that these carbocations are at least closely related to the active species. Their complete identification would need NMR studies.

The relative stabilities of ester and carbocationic species formed by reaction between triflic acid and various monomers are strongly influenced by the substituents of the double bond. Whereas for styrene the stable species is probably the ester, for 1,1diphenylethylene it is the carbocation (with homoconjugation of part of the acid with the counterion. ${ }^{56}$ ) The situation is intermediate for $p$ methoxystyrene and $p$-isopropyl- $\alpha$-methylstyrene, that give high yields of carbocations of lower stability.

\section{Multimodal Distributions}

They have been observed mainly for styrene polymerizations, and it was stated that they occurred when the counter ion is a strong nucleophile as for polymerizations initiated by protonic acids or by iodine, and did not with Friedel Crafts derivatives.

Multimodal distributions were first observed for the slow reactions occurring with perchloric $\mathrm{acid}^{46}$ or triflic $\mathrm{acid}^{48}$ (when monomer concentrations were high enough), but not for the fast ones involving free cations. ${ }^{35,36}$ Bimodal distributions were found for polymerizations realized in solvents of medium dielectric constants (DC of about 10) such as $\mathrm{CH}_{2} \mathrm{Cl}_{2}$ and their mixtures. ${ }^{48}$ In non polar solvents, only the low molecular weight polymer was formed, and in solvents. of high DC, only the high mol wt one. ${ }^{48} \mathrm{~A}$ suggested explanation was the simultaneous existence of two different types of active species, but it is necessary to assume that the interconversion of the two species is relatively slow.

Let us see now whether a spontaneous ionization of an ester might give a carbocation with a lifetime long enough to give mol wt high enough. The recombination rate constant $k_{\mathrm{a}}$ of the ionic species is diffusion controlled and of the order of $10^{9}$. The lifetime of the cations is $\tau=1 /\left(k_{\mathrm{a}}\left[\mathrm{X}^{-1}\right]\right),\left[\mathrm{X}^{-}\right]$being the concentration of free counterions $\left[\mathrm{X}^{-}\right]$, equal to that of $\left[\mathrm{P}^{+}\right]$. The highest $\left[\mathrm{P}^{+}\right]$concentration that may be undetected by UV is of the order of $10^{-6} \mathrm{M}$, so that $\tau=1 /\left(10^{9} \times 10^{-6}\right) \sim 10^{-3}$ (or higher than that value). The kinetic chain length is $\lambda=k_{\mathrm{p}}{ }^{+} \tau[\mathrm{M}]$, and if $k_{\mathrm{p}}{ }^{+}$is for example equal to $2 \times 10^{5},{ }^{37} \lambda=200$ [M].

This agrees rather well with the influence of $[\mathrm{M}]_{0}$ on the mol wt of the high mol wt fraction formed in styrene polymerization in $\mathrm{CH}_{2} \mathrm{Cl}_{2}$ by $\mathrm{ClO}_{4} \mathrm{H}$ at $0^{\circ} \mathrm{C}^{47}: M_{n} \simeq 3000$ for $[\mathrm{M}]_{0}=0.15$, and $M_{n} \simeq 10,000$ for $[\mathrm{M}]_{0}=0.62$. However, in order for the mol wt of this fraction to be monomer dependent, one has to assume that a $[\mathrm{M}]$ independent chain-breaking reaction occurs at the end of the growth over free ions, e.g., recombination with counter ion or eventually spontaneous transfer reaction. The gradual disappearance of this fraction when the D.C. decreases may be understood by a lowering of the ionization rate, and the latter would naturally be suppressed-as was observed-in the presence of added common ion salt. ${ }^{46,48}$

On the other hand, the formation of the low mol wt species (with a mol wt independent of $[\mathrm{M}]_{0}$ ) could be the consequence of transfer to monomer, occurring preferentially on the other types of active centres. There is still much uncertainty about the nature of these "apparently non-ionic species." They might be the esters growing through a "true" pseudocationic polymerization, or the esters protonated by acid molecules. Each monomer insertion on transient ionized or polarized species might be followed by a "collapse" back to the ester, that would be a dormant polymer. The presence of an acid molecule associated to the ester might favor transfer to monomer in this case. It would certainly be interesting to prepare and identify a pure ester in 
order to see if it is active. But there is always the possibility that it is unstable and in equilibrium with some acid, and it would be then difficult to conclude.

It should be pointed out that the formation of multimodal polymer samples is not restricted, as was thought before ${ }^{57}$ to initiation by protonic acids and by iodine (or their derivatives). For example, trimodal distributions have been observed for the fast polymerization of $p$-methoxystyrene in $\mathrm{CH}_{2} \mathrm{Cl}_{2}$ by both $\mathrm{CF}_{3} \mathrm{SO}_{3} \mathrm{H}$ and $\Phi_{3} \mathrm{C}^{+}, \mathrm{SbCl}_{6}{ }^{-} .{ }^{54}$ Polymodality changes significantly with temperature and with the solvent. There is an increase of the high mol wt population when the temperature is lowered ${ }^{54}$ and also with an increasing polarity of the solvent. ${ }^{58}$ Two of the populations are responding to a salt effect while the third one shows little variation. One might consider the existence of different species solvated by the monomer, the polymer or the solvent, without excluding the presence of covalent-type species (for $\mathrm{CF}_{3} \mathrm{SO}_{3} \mathrm{H}$ ), but the main problem still remains that of their slow interconversion. Moreover, it seems necessary, before proposing a quantitative kinetic formulation of the results, to verify whether all populations are formed really simultaneously during the reactions. This is not easy since those have half lives of the order of $10 \mathrm{~s}$, and this question will be eventually answered by using an experimental system with continuous flow, that permits to isolate terminated samples at various conversions.

Polymerizations Initiated with Acetyl Perchlorate. The results observed for polymerizations of styrene initiated by $\mathrm{ClO}_{4} \mathrm{Ac}$ are similar to those obtained with $\mathrm{ClO}_{4} \mathrm{H}$ or $\mathrm{CF}_{3} \mathrm{SO}_{3} \mathrm{H}$. Recently, an end-capping method was proposed for the determination of the concentration of the propagating species and therefore of $k_{\mathrm{p}}{ }^{59}$ The polymerizing mixture was reacted with sodium naphtoxide (in suspension in $\mathrm{CH}_{2} \mathrm{Cl}_{2}$ ) and the polymer analysed by GPC. UV detection permitted to measure the concentration $\left[\mathrm{P}^{*}\right]$ of the naphtoxy end groups, that was considered to be equal to that of the active species. [ $\left.\mathrm{P}^{*}\right]$ did not vary significantly with conversion and the first order law in $[\mathrm{M}]$ showed a constant active centres concentration. However, this does not prove that $\mathrm{P}^{*}$ represent active centres, and the apparent $k_{\mathrm{p}}$ deduced from the rate and $\left[\mathrm{P}^{*}\right]$ is only equal to 1.5 $1 \mathrm{~mol}^{-1} \mathrm{~s}^{-1}$ (at $0^{\circ} \mathrm{C}$ for $[\mathrm{M}]_{0}=0.5$ and $[\mathrm{C}]_{0}=0.002$ ) which is much lower than what was observed by the same authors for lower monomer concentrations $\left(k_{\mathrm{p}} \sim 10^{4}\right.$ for $\left.[\mathrm{M}]_{0} \sim 10^{-3}\right) .{ }^{59}$

A bimodal distribution was observed for the polymer (for $[M]=0.25 \mathrm{M}$ ), with the low mol wt population containing nearly all the naphtoxycapped chains, and those being principally oligomers of $\overrightarrow{\mathrm{DP}}_{n}$ one to 8 . This shows that the ester groups were mainly at the end of these oligomers, that might very well be inactive. However, the presence of two families of higher mol wt macromolecules has to be accounted for. One might imagine that the high mol wt population has grown on free carbocations formed by spontaneous ionization of esters (as suggested above), that terminate eventually (by recombination) by spontaneous transfer or by reaction with water. This possibility is supported by the increase of both this population and of the global rate with an increase of the solvent dielectric constant. The low mol wt population might be formed on "protonated esters."

With $p$-methoxystyrene, ${ }^{57}$ initiation by $\mathrm{ClO}_{4} \mathrm{Ac}$ in $\mathrm{CH}_{2} \mathrm{Cl}_{2}$ gave very high yield of cationic species $\mathrm{Y}^{+}$ (absorption at $380 \mathrm{~nm}$ ) which is compatible with a complete consumption of the initiator on the basis of an estimated value for the extinction coefficient. With this assumption, the calculated $k_{\mathrm{p}}$ was equal to $55,0001 \mathrm{~mol}^{-1} \mathrm{~s}^{-1}$ at $30^{\circ} \mathrm{C}$ (for $[\mathrm{M}]_{0}=5 \times 10^{-3} \mathrm{M}$ ). A decrease of the dielectric constant (by $\mathrm{CCl}_{4}$ addition) caused a decrease of $\mathrm{Y}^{+}$concentration and an increase of the apparent $k_{\mathrm{p}}$ (based on $\mathrm{Y}^{+}$) Similarly, addition of the salt $n$ - $\mathrm{Bu}_{4} \mathrm{NClO}_{4}$ lowered $\mathrm{Y}^{+}\left(\right.$e.g., by $20 \%$ ) but increased $k_{\mathrm{p}}$ (by $\left.100 \%\right)$. These results were explained by the promotion of the formation, either by the salt or by a lowering of the D.C., of "invisible" propagating species. But this is difficult to understand since these non ionic species should have a higher reactivity than the ionic ones.

\section{STABILITIES OF ACTIVE CENTRES AND POSSIBILITIES OF LIVING CATIONIC POLYMERIZATIONS}

Since carbocations present in most polymerizing systems have not been identified by direct physicochemical methods, it has not been generally possible to distinguish between active species stable during the whole polymerization and inactive 
"sleeping" species that become active for very short periods. In this respect, it is however interesting to discuss briefly what could be deduced from the direct observation of various types of ionic species, particularly about their lifetime.

The only type for which there is little doubt about their nature have been formed by radio or photochemical initiation in high purity conditions. These free carbocations have been distinguished from the corresponding carbanions by selective inhibition experiments, that also permitted to measure their lifetimes (that could also be deduced from conductivity measurements). Those are very short, of the order at room temperature of $10^{-2}$ to $10^{-1} \mathrm{~s}$ according to the dose rate for continuous initiation of the bulk monomers (styrene, $\alpha$-methylstyrene, IBVE) by ionizing radiations, ${ }^{60}$ and about $10^{-6}$ to $10^{-5} \mathrm{~s}$ for the benzyl cation formed by electron pulse in $\mathrm{CH}_{2} \mathrm{ClCH}_{2} \mathrm{Cl}$. ${ }^{61}$ The lower value in the second case was a consequence of the much higher carbocation concentration $\left(10^{-7}\right.$ to $10^{-6} \mathrm{M}$ against about $10^{-10}$ to $10^{-12} \mathrm{M}$ in the first one) leading to a higher recombination rate with the anions.

We have seen above that chemically initiated transient species could be observed in chlorinated solvents for styrene, with lifetimes of the order of $1 \mathrm{~s}$ or shorter. The lifetimes are longer for $p$ methoxystyrene and $p$-isopropyl- $\alpha$-methylstyrene, but their exact nature is still not proven.

A discussion of the absence of living polymerizations in carbocationic polymerizations has been made by Pepper, ${ }^{46}$ who explained it by the occurrence of termination reactions involving the counter-ion and of extensive transfer reactions. In his opinion, the only hope to suppress them was by using monomer giving very stabilized carbocations, such as $p$-methoxystyrene or vinylcarbazole.

However, more recent results about the growth of molecular weights with conversion in some systems have been interpreted by the existence of living ${ }^{62}$ or "quasi living" 63 polymerizations, and we shall examine some of the evidence given for polymerizations involving either iodine or Friedel Crafts catalysts.

\section{Polymerizations Initiated by Iodine or by the System $I H-I_{2}$}

First, I would like to discuss the terminology used. As pointed out by Pepper, ${ }^{46}$ a truly living polymerization according to the definition of $\mathbf{M}$.
Szwarc occurs if $R_{\mathrm{i}} \gg R_{\mathrm{p}}, R_{\mathrm{t}}=0$ and $R_{\mathrm{tr}}=0$. With such conditions, the living polymer sample will consist only of polymer chains of similar mol wt, all containing one (or two) active centres. This is naturally compatible, as for anionic polymerizations, with the existence of several types of active species in equilibrium. As a limit case, a temporary termination reaction, giving an end-group that may react again to give an active centre, may be compatible with the existence of a living system, e.g.,

$$
\mathrm{M}_{n}^{+}, \mathrm{M}_{t} \mathrm{X}_{n}^{-} \rightleftarrows \mathrm{M}_{n} \mathrm{X}+\mathrm{M}_{t} \mathrm{X}_{n-1}
$$

This type of temporary termination seems to be the case for polymerizations of either styrene derivatives or vinyl ethers by iodine for which there is some evidence that it involves active centres of the type $\sim \mathrm{CH}_{2}-\mathrm{CH}, \mathrm{I}_{3}$, even if there is no agreement $R$

about their way of formation ${ }^{64}$

$$
\mathrm{M}_{n}{ }^{+}, \mathrm{I}_{3}{ }^{-} \rightleftarrows \mathrm{M}_{n} \mathrm{I}+\mathrm{I}_{2}
$$

But the mol wt variation is different for vinyl ethers and for styrene, extensive chain transfer occurring with the latter.

The growth of $M_{n}$ with successive monomer addition for the polymerization of $n$-butyl vinyl ether at $-60^{\circ} \mathrm{C}$ in $\mathrm{CH}_{2} \mathrm{Cl}_{2}$ was noted by Johnson and Young ${ }^{65}$ who suggested that the activity of the polymer chains was retained, with active chains in equilibrium with inactive ones. But these authors also considered the possibility of incorporation into the final polymer of terminated polymer chains having unsaturated chain ends. This looks quite possible since 1,2-disubstituted monomers, such as alkyl propenyl ethers (or anethole) also polymerize in the same conditions. An increase of mol wt with conversion had also been observed by Higashimura et al. for $p$-methoxystyrene in $\mathrm{CCl}_{4}$ at $0^{\circ} \mathrm{C}$, and attributed to the presence of long lived non-dissociated active species. ${ }^{66}$ However, in this system, the curve giving the variation of $M_{n}$ with conversion did not extrapolate to the origin, and the number of polymer chains produced per mole of iodine $N=$ $[\mathrm{M}]$ consumed $/\left(\overline{\mathrm{DP}}_{n} \times[\mathrm{C}]_{0}\right)$ increased with conversion. But by working with $p$-methoxystyrene at a lower temperature $\left(-15^{\circ} \mathrm{C}\right)$ in $\mathrm{CCl}_{4}$ or $\mathrm{CH}_{2} \mathrm{Cl}_{2}$ containing the common-ion salt $n$ - $\mathrm{Bu}_{4} \mathrm{NI}$, the number of chains per initiator molecule went down to values between 0.2 and 0.8 , showing that transfer had strongly decreased, and further addition of 
isobutyl vinyl ether at $-15^{\circ}$ gave a polymer containing a significant proportion of block copolymer (blocking efficiency of $39 \%$ in $\mathrm{CCl}_{4}$ ).

In their communication in Ghent (1983), Sawamoto and Higashimura ${ }^{67}$ described the polymerization of IBVE in hexane at $-15^{\circ}$ initiated by $\mathrm{HI} / \mathrm{I}_{2}$. With $\mathrm{IH}$ used in equimolar amount with $\mathrm{I}_{2}$, the polymerization is more rapid and proceeds without an induction period. $M_{n}$ grows with conversion, following a linear curve passing through the origin and having a slope inversely proportional to IH (or $\mathrm{I}_{2}$ ) concentration. The number of polymer chains per IH is equal to one, and the $M_{w} / M_{n}$ ratio is always small (1.08 to 1.04$)$ for conversions varying from 38 to $95 \%$. Thus, this system presents the features of an "almost perfect living polymerization in which chain transfer and termination are absent." Moreover, the same initiator was used to prepare block copolymers of IBVE with $p$ methoxystyrene with a blocking efficiency of $80 \%{ }^{68}$

However, it should be noted that for this system showing a linear increase in mol wt with conversion the highest $\overline{\mathrm{DP}}_{n}$ given for poly IBVE are of the order of 100 , and that for values of $k_{\mathrm{trm}} / k_{\mathrm{p}}$ lower than $5 \times$ $10^{-3}$, transfer would not be detected. And if very few transferred chains were formed, they might have been incorporated into the polymer by copolymerization. A more detailed comparison of $\overline{\mathrm{DP}}_{n}$ obtained by VPO and by calibrated GPC might give some information on possible branching, but this is not sure since the mol wt are so low.

The variation of mol wt looked similar for $\mathrm{N}$ vinylcarbazole (NVC) polymerization by iodine alone at $-78^{\circ} \mathrm{C}$ in $\mathrm{CH}_{2} \mathrm{Cl}_{2}$, in the presence of $n$-Bu $\mathrm{Bu}_{4}{ }^{69}$ For successive monomer additions, $M_{n}$ grew linearly with $[\mathrm{NVC}] /\left[\mathrm{I}_{2}\right]$, but the highest $\overline{\mathrm{DP}}_{n}$ were of about 130 . It has already been found however that transfer reactions may decrease strongly when temperature is low enough. For the polymerization of $\mathrm{NVC}$ in $\mathrm{CH}_{2} \mathrm{Cl}_{2}$ at $-70^{\circ} \mathrm{C}$ initiated with $\mathrm{C}_{7} \mathrm{H}_{7}{ }^{+} \mathrm{SbF}_{6}{ }^{-}$, Rooney ${ }^{70}$ found that the experimental $\overline{\mathrm{DP}}_{n}$ (of 1,500 ) were only about half the theoretical ones $(\sim 2,800)$ which shows that the transfer constant $k_{\mathrm{trM}} / k_{\mathrm{p}}$ was of the order of $10^{-3}$ at most and that for much lower $\overline{\mathrm{DP}}_{n}$, the effect of transfer would not appear.

The situation with vinyl ethers initiated by carbocationic species shall be discussed again later. It seems that when counter ions other than $\mathrm{I}_{3}{ }^{-}$are involved, transfer reactions are important at $-15^{\circ} \mathrm{C}$, and that for the $\mathrm{I}_{2}-\mathrm{IH}$ system transfer is at least considerably lowered. It would be however interesting to see what happens for higher conversions and mol wt.

It is apparent from the foregoing discussion that the proof of the existence of living polymers might only be deduced from precise informations about the absence of chain transfer, and that these informations may be obtained only if the mol wt are large enough. If only bimolecular transfer to monomer occurs, the relationship between $\overline{\mathrm{DP}}_{n}$ and $k_{\mathrm{trM}} / k_{\mathrm{p}}$ is the following ${ }^{74}$ if $[\mathrm{M}]_{\mathrm{c}}$ and $[\mathrm{I}]_{\mathrm{c}}$ are the concentration of monomer and initiator consumed

$$
\frac{1}{\overline{\mathrm{DP}}_{n}}=\frac{[\mathrm{I}]_{\mathrm{c}}}{[\mathrm{M}]_{\mathrm{c}}}+\frac{k_{\mathrm{trM}}}{k_{\mathrm{p}}}
$$

If $[\mathrm{I}]_{\mathrm{c}} /[\mathrm{M}]_{\mathrm{c}}$ is large enough, as has been generally the case for these types of experiments, it is obvious that the precision on $k_{\mathrm{trM}} / k_{\mathrm{p}}$ measurements or the effect of monomer transfer become very low. For example, we have found that $p$-methoxystyrene polymerization in $\mathrm{CH}_{2} \mathrm{Cl}_{2}$ occurs at $-15^{\circ} \mathrm{C}$ with a value of $k_{\mathrm{trM}} / k_{\mathrm{p}} \sim 2 \times 10^{-5} .^{74}$ If $\left[\mathrm{M}_{\mathrm{c}}\right] /\left[\mathrm{I}_{\mathrm{c}}\right]=200,[\mathrm{I}]_{\mathrm{c}} /$ $[\mathrm{M}]_{\mathrm{c}}=5 \times 10^{-3}$ and the effect of transfer on $\overline{\mathrm{DP}}_{n}$ shall not be detectable. High yields of block copolymers might also be obtained (after a second monomer addition on the low polymers formed initially).

It should be pointed out however that transfer constants have been generally obtained by making unproven assumptions about the order of the reaction with respect to active centres and monomer concentrations.

\section{Various Situations Explaining the Growth of $M_{n}$ with} the Quantity of Consumed Monomer

There are several possible causes for such an increase of $M_{n}$ :

1) Termination and transfer are absent, and the system is truly living.

2) Termination and transfer occur, but are not detected experimentally because the $M_{n}$ are too low.

3) There is not transfer, and termination occurs, but slowly enough to have a complete conversion. The experimental $M_{n}$ are identical with the theoretical $M_{n}$, and it has been calculated, and found for anionic systems, that if initiation is fast compared to propagation, relatively narrow Poisson distributions may be obtained. But the occurence of 
significant terminations would not fit with extremely narrow distributions $\left(M_{w} / M_{n}<1.1\right)$

In fact, cases 1) 2), and 3) are not easily distinguished experimentally, since the deviations with the theoretical $M_{n}$ are small if transfer is not very important or if the mol wt are low enough.

4) Reversible termination; no transfer. Termination occurs, but giving an end group (e.g., terminal halide, $c f$., $\mathrm{p}$ 66) that may be reinitiated. If reinitiation takes place several times during the growth of all macromolecules, this is not very different from case 1) when there is a multiplicity of ionic species. The distribution will be more or less narrow according to the frequency of reinitiation.

5) Termination is absent, or reversible. All transfer reactions are completely reversible.

6) Transfer and termination occur but giving terminal double bonds that may copolymerize, giving branched polymers.

In a series of publications describing "quasiliving polymerizations" for which a regular increase of $M_{n}$ with the amount of monomer added was found provided monomer concentration was kept very low, Kennedy eta $l^{63}{ }^{6}$ explained their results by considering a combination of case 4) (reversible termination) and case 5) (reversible chain transfer).

I shall discuss successively the case of vinyl ethers, that were polymerized in $\mathrm{CH}_{2} \mathrm{Cl}_{2}$ at very low temperatures (e.g., -70 and $-90^{\circ} \mathrm{C}$ ) and those of isobutylene and styrene derivatives, generally polymerized at $-50^{\circ}$ in mixed solvents, since I believe that the interpretation of the results should be different.

\section{Polymerizations Initiated by Friedel Crafts Catalysts and Their Derivatives}

Vinyl Ethers. A quasi-living polymerization of IBVE has been said to occur only with slow monomer addition at -70 or $-90^{\circ} \mathrm{C}$, but not at $-50^{\circ} \mathrm{C} .^{71}$ The supposedly bifunctional initiator was 1,4-dicumyl chloride (DCC) associated with $\mathrm{Ag}^{+}$ $\mathrm{SbF}_{6}{ }^{-}$. As long as the quantity of monomer added was not too high (e.g., $5 \times 10^{-2} \mathrm{~mol}$ for $5 \times 10^{-4}$ mol of DCC at $-70^{\circ} \mathrm{C}$ ) the number of polymer chains per DCC did not change much and was near to 1 at $-70^{\circ} \mathrm{C}$ and near to 2 at $-90^{\circ} \mathrm{C}$. The mol wt distributions were characterized by $M_{w} / M_{n}$ ratios ranging from 1.4 to 1.7 at $-70^{\circ} \mathrm{C}$, as expected for a bifunctional initiator if transfer is not important. However, the variation of $M_{n}$ with polymer yield showed a deviation from linearity above $\overline{\mathrm{DP}}_{n}=220$ at -70 and 400 at $-90^{\circ}$, and it is worthwhile to examine what was known about chain transfer occurring in similar conditions. For IBVE polymerized with $\mathrm{Ph}_{3} \mathrm{C}^{+}, \mathrm{SbCl}_{6}{ }^{-}$in $\mathrm{CH}_{2} \mathrm{Cl}_{2},{ }^{72}$ the activation energy of the transfer to monomer was 8.9 $\mathrm{Kcal} \mathrm{mol}{ }^{-1}$ and $E_{\mathrm{trM}}-E_{\mathrm{p}}$ was equal to $3, k_{\mathrm{trM}} / k_{\mathrm{p}}$ being equal to $9 \times 10^{-3}$ at $-40^{\circ} \mathrm{C}$. Extrapolations give $k_{\mathrm{trM}} / k_{\mathrm{p}}=1.6 \times 10^{-3}$ at $-70^{\circ} \mathrm{C}$ and $5 \times 10^{-4}$ at $-90^{\circ} \mathrm{C}$. The results obtained with the $\mathrm{SbF}_{6}{ }^{-}$counterion agree satisfactorily with $k_{\mathrm{trM}} / k_{\mathrm{p}}$ of these order of magnitude. It then does not seem that the progressive monomer addition would be necessary to "suppress" transfer at those temperatures and to obtain the theoretical molecular weights, as long as they are low enough. It would however be interesting to see what may be obtained with a simple mixing of the reagents, made at an initial temperature low enough so that it does not rise above $-70^{\circ} \mathrm{C}$ during the reaction.

With respect to the various reasons that may lead to an increase of $M_{n}$, what is the situation for these polymerizations? It is particularly interesting that in that case, a calibration of the GPC curve (that gives $M_{n}$ in equivalent polystyrene) was made on some samples by laser light scattering and showed an agreement within $10 \%$ with the equivalent $M_{n}$. This seems to rule out the possibilities of extensive ramifications, that would be necessary if the reaction corresponded to case 6). It does not seem necessary to introduce hypothesis 4 and 5 to explain these results, and it looks likely that they correspond to cases 2 or 3 , transfer and termination reactions being much reduced, but not completely suppressed, at these low temperatures.

\section{Styrene Derivatives and Isobutylene}

This series of polymerizations of $\alpha$-methylstyrene, styrene, substituted styrenes, indene and isobutylene have been generally made at temperatures not lower than $-50^{\circ} \mathrm{C}$, either in $\mathrm{CH}_{2} \mathrm{Cl}_{2}$ or in $\mathrm{CH}_{2} \mathrm{Cl}_{2}$-hydrocarbon mixtures. ${ }^{63}$ Using as initiators $\mathrm{BCl}_{3}$ or $\mathrm{TiCl}_{4}$, associated or not with organic halides, slow monomer addition led to a progressive increase of mol wts and sometimes to a narrowing of their distribution with conversion.

It has been shown (see above part I) that transfer reactions are significant at $-50^{\circ} \mathrm{C}$ in the mixture $\mathrm{CH}_{2} \mathrm{Cl}_{2}-$ methylcyclohexane (initiation by $\mathrm{RCl}+$ $\mathrm{AlEt}_{2} \mathrm{Cl}$ ), with $k_{\mathrm{trM}} / k_{\mathrm{p}}$ of about $6 \times 10^{-4}$ for in- 
dene, $2 \times 10^{-3}$ for $\alpha$-methylstyrene and $2.4 \times 10^{-3}$ for styrene. ${ }^{31}$

The results obtained for the slow monomer additions were explained by Kennedy et al. by making two hypothesis.

a) Equilibrated termination reaction. This has been discussed above.

b) Equilibrated transfer reactions, realized by adding the monomer very slowly in order to keep its concentration very low.

The two types of transfer (to monomer and "spontaneous") were considered:

$$
\begin{aligned}
& \text { 1) } \mathrm{M}_{n}{ }^{+} \mathrm{X}^{-}+\mathrm{M} \underset{k_{\mathrm{tr}}=}{\stackrel{k_{\mathrm{trm}}}{\rightleftarrows}} \\
& \text { 2) } \mathrm{M}_{n}^{+} \mathrm{X}^{-} \underset{k_{+\mathrm{H}}}{\stackrel{k_{-\mathrm{H}}}{\rightleftarrows}} \sim \mathrm{C}=\mathrm{C}+\mathrm{H}^{+} \mathrm{X}^{-}
\end{aligned}
$$

followed by 2 bis)

$$
\mathrm{H}^{+} \mathrm{X}^{-}+\mathrm{M} \underset{k_{-\mathrm{H}}}{\stackrel{k_{+\mathrm{H}}}{\rightleftarrows}} \mathrm{HM}^{+} \mathrm{X}^{-} \underset{k_{\mathrm{p}}}{\stackrel{\mathrm{M}}{\rightleftarrows}} \mathrm{HM}_{2}^{+} \mathrm{X}^{-}
$$

It was said that in the virtual absence of monomer, equilibria 1 and 2 were shifted to the left, and that chain transfer could be suppressed by continuous monomer addition at a very low rate, the incoming monomer being exclusively consumed by propagation. Case 2 is pratically equivalent to case 1 if reaction 2 bis also is an equilibrium.

However some doubts may be expressed about the establishment of all these equilibria. For example, $\mathrm{HM}^{+} \mathrm{X}^{-}$reacts competitively with terminal double bonds and with the monomer, this last reaction displacing the equilibria towards the right. The reverse of reaction 1) will be favored only if $\mathrm{M}$ concentration is kept lower than that of the terminal double bonds. This is certainly not easy to achieve, and it is difficult to prove the existence of such a situation. The reaction of $\mathrm{HM}^{+} \mathrm{X}^{-}$with monomer might be preferred.

If we consider now reversible reactions 2 and 2 bis, it is true that if $[\mathrm{M}]$ decreases, the stationary concentration of $\mathrm{H}^{+} \mathrm{X}^{-}$will be higher, shifting equilibrium 2) towards the left. But low monomer concentration imply longer reaction times to consume the same amount of monomer, and equilibrium will probably never be reached, with an in- crease of the number of terminal double bonds with time.

In fact, the increase in the number of polymer chains that was observed for several of these systems ${ }^{63}$ when larger quantities of monomer polymerized showed that transfer reactions did occur. In some cases, (e.g., isobutylene) the linear variation of $M_{n}$ with the quantity of polymerized monomer did not pass through the origin. In other cases (e.g., $p$ tert-butylstyrene) the linearity was observed only up to relatively low $\overline{\mathrm{DP}}_{n}$. It is difficult to draw definite conclusions from these data.

Moreover, if equilibria 1 and 2 were shifted towards the left, the concentration of $\mathrm{HM}^{+} \mathrm{X}^{-}$ would be lower than that of $\mathrm{M}_{n}^{+} \mathrm{X}^{-}$, and the reaction of this growing species with the terminal double bond should be more probable. This corresponds to case 6) for which branched polymers are formed from the "macromers" formed by transfer and termination.

This seems to me to be a very likely explanation of the results observed by Kennedy et al. for $\alpha$ methylstyrene and styrene, for which the linearity of the variation of $\overline{\mathrm{DP}}_{n}$ with monomer consumption was observed up to rather high $\overline{\mathrm{DP}}_{n}$. It was the case for example up to $D P$ of about 700 for $\alpha$-methylstyrene polymerization at $-50^{\circ} \mathrm{C}$ in the mixture $\mathrm{CH}_{2} \mathrm{Cl}_{2}$-methylcyclohexane (initiation by $\mathrm{BCl}_{3}$ and cumyl chloride). The number of final macromolecules was less than what might have been predicted from the transfer constant to monomer in batch conditions at this temperature. ${ }^{31}$ These results also show that slow monomer addition has probably played an important role: a low monomer concentration will on one hand increase the relative concentration of double bonds belonging to polymer chains, and on the other hand increase the reaction time, both factors favoring the incorporation of the terminal double bonds into the final polymer. It is also possible that for these monomers, case 4 is operative, that is, reinitiation from benzylic halides formed by temporary termination.

Such a copolymerization involving terminal double bonds and the formation of branched macromolecules (that was not considered by Kennedy et $a l .{ }^{63}$ ) might also explain the narrowing of the mol wt distribution. In this respect, very interesting observations have been made by Bywater et al. ${ }^{73}$ for the polymerization of pentamethylstyrene at $-70^{\circ} \mathrm{C}$ in $\mathrm{CH}_{2} \mathrm{Cl}_{2}$ with the system $\mathrm{SnCl}_{4}-\mathrm{HCl}$. 
Polymerizations were completed in a few minutes. However, very narrow distributions were obtained, and an examination of mol wt variation with time showed a strong growth of $M_{n}$ for only a small increase of conversion, together with a strong narrowing of the distribution (e.g., from 1.61 to 1.33 , or 1.52 to 1.10 for a longer time). This shows that in this case, the increase of mol wt was essentially the consequence of a post-polymerization of the low polymers formed at the beginning, and that this post polymerization could be rather fast.

It should be admitted that the data available are generally not sufficient to permit to distinguish between the various possibilities that might explain the growth of mol wt with the amount of monomer polymerized. The reversibility of termination looks quite likely in the polymerization of vinyl ethers by $\mathrm{IH}+\mathrm{I}_{2}$, and might occur also for other systems. But in order to distinguish between really reversible transfer reactions and a copolymerization of the ethylenic end groups, a series of complementary informations is needed.

a) What are the type and concentrations of the end groups of the polymer chains formed at low conversion, and what changes do occur for higher conversions?

b) For each system, do the polymer formed in a first step reinitiate or not the polymerization of a new monomer added, with a growth (or not) of mol wt?

c) Are the final polymers branched or not? This might be verified by characterizing them by both colligative methods and light scattering (or at least GPC calibrated with model samples).

In my opinion, the name of living polymers (or living polymerizations) should be reserved to situations where stable active centres are present at the end of each macromolecule. The naming "quasiliving polymerization" might be quite appropriate for cases (as described theoretically by Kennedy) in which reinitiation occurs starting from the chain-ends that are not active by themselves.

Acknowledgements. I want to thank Drs. G. Sauvet and K. Matyjaszewski for their comments and for their interesting suggestions.

\section{REFERENCES}

1. P. H. Plesch, "'The Chemistry of Cationic
Polymerization," Pergamon Press, Oxford, 1963. See particularly Chapter 4.

2. J. M. Moulis, J. Collomb, A. Gandini, and H. Chéradame, Polym. Bull., 3, 197 (1980).

3. J. P. Kennedy, J. Polym. Sci., A, 1, 6, 3139 (1966).

4. J. P. Kennedy, J. Macromol. Sci. Chem., A3, 861 (1969).

5. A. Gandini and H. Chéradame, Adv. Polym. Sci., 34-35, 172 (1980).

6. P. Sigwalt and H. Chéradame, presented at the IUPAC International Symposium on Macromolecules, Tokyo 1966, P 2-1-06; Bull. Soc. Chim., 843 (1970).

7. T. Diem and J. P. Kennedy, J. Macromol. Sci. Chem., A12, 1359 (1978).

8. M. Marek, J. Polym. Sci., Polym. Symp., 56, 149 (1976).

9. A. Gandini, H. Chéradame, and P. Sigwalt, Polym. Bull., 2, 731 (1980).

10. M. Marek, J. Pecka, and V. Malaska, Abstracts, the 6th International Symposium on Cationic Polymerization, Ghent, 1983, p 21.

11. D. W. Grattan and P. H. Plesch, Makromol. Chem., 181, 751 (1980).

12. M. Chmelir and M. Marek, J. Polym. Sci., Polym. Symp., 22, 177 (1968).

13. M. Masure, A. H. Nguyen, G. Sauvet, and P. Sigwalt, Makromol. Chem., 182, 2695 (1981).

14. M. Masure, G. Sauvet, and P. Sigwalt, J. Polym. Sci., Polym. Chem., 16, 3065 (1978).

15. M. Masure, G. Sauvet, and P. Sigwalt, Polym. Bull., 2, 699 (1980).

16. M. Masure, P. Sigwalt, and G. Sauvet, Makromol. Chem. Rapid. Commun., 4, 269 (1983).

17. J. P. Kennedy, T. Kelen, S. C. Guhaniyogi, and R. T. Chou, J. Macromol. Sci., Chem., A18, 129 (1982).

18. J. P. Kennedy and R. T. Chou, J. Macromol. Sci., Chem., A18, 11 (1982).

19. J. P. Kennedy and R. T. Chou, J. Macromol. Sci., Chem., A18, 17 (1982).

20. J. P. Kennedy and R. T. Chou, J. Macromol. Sci., Chem., A18, 47 (1982).

21. J. P. Kennedy and E. Maréchal, "Carbocationic Polymerization," John Wiley, New York, N. Y., 1982.

22. See ref 5 , pp $174-182$.

23. P. K. Bossaer, E. J. Goethals, P. J. Hackett, and D. C. Pepper, Eur. Polym. J., 13, 489 (1977).

24. J. P. Kennedy and R. A. Smith, J. Polym. Sci., Polym. Chem., 18, 1523 (1980).

25. J. P. Kennedy and R. A. Smith, J. Polym. Sci., Polym. Chem., 18, 1539 (1980).

26. O. Nuyken, S. D. Pask, and M. Walter, Polym. Bull., 8, 451 (1982).

27. S. D. Pask and O. Nuyken, Polym. Bull., 8, 457 (1982).

28. O. Nuyken, S. D. Pask, and A. Vischer, Makromol. 
Chem., 184, 553 (1983)

29. J. P. Kennedy, J. Appl. Polym. Symp., 30, 30 (1977).

30. P. Sigwalt, A. Polton, and M. Miskovic, J. Polym. Sci., Polym. Symp., 56, 13 (1976).

31. B. Pary, M. Tardi, A. Polton, and P. Sigwalt, Preprints, "New Developments in Cationic Polymerizations," 1st European Discussion Meeting on Polymer Science, The French Polymer Group and the CNRS, Strasbourg, 1978, p 52.

32. M. Samsami, M. Tardi, A. Polton, and P. Sigwalt, Eur. Polym. J., 19, 287 (1983).

33. M. Tazi, A. Polton, M. Tardi, and P. Sigwalt. To be published.

34. H. Chéradame, A. H. Nguyen, and P. Sigwalt, $P$. Polym. Sci., Polym. Symp., 56, 335 (1976).

35. J. P. Lorimer and D. C. Pepper, Proc. R. Soc. London Ser. A, 351, 551 (1976).

36. T. Kunitake and K. Takarabe, Polym. J., 10, 105 (1978).

37. T. Kunitake and K. Takarabe, Macromolecules, 2, 1067 (1979).

38. M. Chmelir, N. Cardona, and G. V. Schulz, Markomol. Chem., 178, 169 (1977)

39. S. Bywater and D. J. Worsfold, Can. J. Chem., 44, 1671 (1966).

40. D. C. Pepper and P. J. Reilly, Proc. R. Soc. London Ser. A, 291, 41 (1966).

41. M. Sawamoto, T. Masuda, and T. Higashimura, Makromol. Chem., 177, 2995 (1976).

42. A. Gandini and P. H. Plesch, J. Chem. Soc., 4826 (1965).

43. A. Gandini and P. H. Plesch, Eur. Polym. J., 4, 55 (1968).

44. P. H. Plesch, Br. Polym. J., 5, 1 (1973).

45. R. Lorin Jones and L. M. Dorfman, J. Am. Chem. Soc., 96, 5715 (1974).

46. D. C. Pepper, J. Polym. Sci., Polym. Symp., 50, 51 (1975).

47. L. M. Leon, P. Altuna, and D. C. Pepper, Eur. Polym. J., 16, 929 (1980).

48. T. Masuda, M. Sawamoto, and T. Higashimura, Makromol. Chem., 177, 12981 (1976).

49. M. Chmelir, Makromol. Chem., 176, 2099 (1975).

50. K. Matjyaszewski, private communication.

51. G. Sauvet and P. Sigwalt, unpublished data.

52. M. Sawamoto and T. Higashimura, Macromolecules,
12, 581 (1979).

53. P. Sigwalt, Proceedings, 5e Convegno Ital. di Scienza della Macromolecole, Pisa, 1983, invited lectures, Vol. 1, p 127.

54. M. Moreau, Thèse 3ème Cycle, Paris (1981).

55. D. Teyssié, M. Villesange, and J. P. Vairon, Polym. Bull., 11, 459 (1984).

56. D. Souverain, A. Leborgne, G. Sauvet, and P. Sigwalt, Eur. Polym. J., 16, 861 (1980).

57. M. Sawamoto, T. Masuda, and T. Higashimura, $J$. Polym. Sci., 16, 2675 (1978).

58. R. Oueslati, Thèse 3ème Cycle, Paris, 1982.

59. M. Sawamoto, A. Furukawa, and T. Higashimura, Macromolecules, 16, 518 (1983).

60. K. Hayashi, Actions Chimiques et Biol. des Rad., 15, 145 (1970).

61. L. M. Dorfman, Macromolecules, 17, 32 (1984).

62. T. Higashimura and O. Kishiro, Polym. J., 9, 87 (1977).

63. A special issue, "Quasiliving Carbocationic Polymerization," J. P. Kennedy, Ed., J. Macromol. Sci. Chem., A18, 1185-1382 (1983).

64. A. Gandini and H. Chéradame, Adv. Polym. Sci., 33-35, 172 (1980).

65. A. F. Johnson and R. N. Young, J. Polym. Sci., Polym. Symp., 56, 211 (1976).

66. T. Higashimura, M. Mitsuhashi, and M. Sawamoto, Macromolecules, 12, 178 (1979).

67. M. Sawamoto, M. Miyamoto, and T. Higashimura, Abstracts, 6th International Symposium on Cationic Polymerization, Ghent, 1983, p 29.

68. T. Higashimura and M. Sawamoto, Abstracts, 6th International Symposium on Cationic Polymerization, Ghent, 1983, p 15.

69. T. Higashimura, Y. Deng and M. Sawamoto, Polym. J., 15, 385 (1983).

70. J. M. Rooney, Makromol. Chem., 179, 165 (1978).

71. M. Sawamoto and J. P. Kennedy, J. Macromol. Sci., Chem., A18, 1275 (1983).

72. F. Subira, G. Sauvet, J. P. Vairon, and P. Sigwalt, $J$. Polym. Sci., Polym. Symp., 56, 221 (1976).

73. D. J. Worsfold, S. Bywater, and P. Black, Abstracts, 6th International Symposium on Cationic Polym. Ghent 1983, p 11.

74. R. Cotrel, G. Sauvet, J. P. Vairon, and P. Sigwalt, Macromolecules, 9, 931 (1976). 